\title{
Embedding Crowd-Vote as Knowledge Source to Support Decision Making on University Program Selection
}

\author{
Ismail, $\mathbf{S}^{1}$, Ismail, $\mathbf{S}^{2}$ \\ ${ }^{1}$ Universiti Tunku Abdul Rahman (UTAR), Faculty of Information and Communication Technology (FICT) \\ ${ }^{2}$ Universiti Kuala Lumpur, Malaysian Institute of Information Technology \\ shahrinaz@unikl.edu.my
}

Article History: Received: 10 November 2020; Revised: 12 January 2021; Accepted: 27 January 2021; Published online: 05 April 2021

Abstract: Crowd-vote has implemented as a part of a university program recommendation system, complementing the aspect
of knowledge management. The recommendation system is developed to support freshmen students' decision making during
program selection and uses for first time of enrolment. The challenges of decision-making among students is formed by
many influential factors like family, agents, universities and others. Popular decision making models include rational,
intuitive, among others. Rational models have series of sequential steps that involve a thinking process, while intuitive
models are more on people experiences and recognition of the pattern based on what people believe and think how it will
work. Other models attempt to combine both rational and intuitive aspects of decision. The challenge is foreseen in capturing
experts' opinion as part of students' decision making, since experts are the good source of knowledge to strengthen the
process. A prototype is developed for this purpose and constructive feedback from experts and students were collected to
examine the significant use of crowd-vote using questionnaire survey. The objectives of this paper are to investigate the use
of crowd-vote in leveraging decision making, and to evaluate the implementation of crowd-vote in supporting decision
making during program selection. The results from expert opinions and students' evaluation are discussed. Keywords:crowd-vote, program recommendation system, experts, knowledge sharing, decision making

\section{Introduction}

According to Gordon and Steele (2015), "undecided students are those students who were unwilling, unable, or unready to make educational and/or vocational decisions" and a "student who has difficulty making any decision, however, may be considered as indecisive". These two groups of students are the potential users of crowd-vote tool in assisting their university program selection in the recommendation system.

Many universities have an advising system or recommendation system, which employ guideline counsellors, people who are tasked with helping students making their choice, including developmental advising, helping them schedule the most suitable programs, assisting in career development, helping them in timely completion of their studies and student's academic performance (Iatrellis, Kameas, \&Fitsilis, 2017). Daramola, et al. (2014) reported that some advisors hold too many students or are overloaded on advising students, in which they are supposed to accommodate a good outcome in terms of understanding, planning and applying strategies for academic success. This issue becomes one of major discussions among previous literature (Unelsrød, 2011), which related to lack of quality provided in advising system and program recommendation system among counsellors or advisors. There are many methods of development to help university students in decision making through program recommendation system, such as web-based tool, intelligence expert advising system and data mining approach, which are currently able to be used in timely decision by set data analysis and data modelling (Feghali, Zbib, \&Hallah, 2011, Brabham, 2010).

It is deemed that the process of counselling and advising potential university students could be improved with an added knowledge value in a program recommendation system. Looking at the potential of embedding a crowdsourcing technique like crowd-vote in a recommendation system, this research strives to respond to the challenge by achieving the following objectives:

- To investigate the use of crowd-vote in leveraging decision making; and

- To evaluate the implementation of crowd-vote in supporting decision making during university program selection among university students.

\section{Related Works}

This section is presented in two sub-sections, to clarify the reviews from literature on crowd-voting and how it relates to recommendation system and knowledge management.

\subsection{Crowdsourcing and Knowledge Management}


Crowdsourcing, in general, is seen as a paradigm to knowledge management (KM) (Callaghan, 2016), and it gives an impact to the knowledge management evolution (Dimitrova \& Scarso, 2017). Its effectiveness in knowledge-based industries has been reported by Devece, Palacios and Ribeiro-Navarrete (2019) in moderating the transformational leadership and organisational learning among small and medium enterprises (SMEs). Crowdsourcing allows companies to cost-effectively solve business problems and innovate faster (Devece, Palacios \& Ribeiro-Navarrete, 2019), in which it moves the attention of KM toward the organisations' external environment as a significant knowledge source (Dimitrova \& Scarso, 2017), hence encouraging knowledge sharing among the experts who are the right people. In a way, getting the knowledge experts involved is a kind of motivation to the experts themselves, as well as enriching the knowledgebase of the current inference system, making the decision output more valuable to the beneficiaries.

In proving the paradigm to KM, Callaghan (2016) proposed a theoretical framework of innovation, in which the principles of crowdsourcing, which are the emergent properties of problem-solving (Mitchell, 1996; Johnson, 1998; Kochugovindan \& Vriend, 1998; Islam, 2016; Smith, 2003; Surowiecki 2004; Hanson, 2000), are applied to research and development. This is to complement and solve the problem of lack of knowledge and innovation failure, which may lead to better decision making. Recent advances in information technology allows large numbers of experts in virtual networks to simultaneously focus on solving problems in hand, creating the concept of pulling the knowledge from the 'crowd' that was previously inaccessible (Callaghan, 2016). In this perspective, the capacity of the crowd can generate a high increase in knowledge creation, as collective knowledge creation can improve, or at least equal, on expert predictions of a case (Surowiecki, 2004).

Many societal problems could be solved almost immediately or real-time, if the potential and capacity of solving the problem by the crowd could be harnessed sufficiently, but it may depend on the number of people contributing to the problem-solving effort (Callaghan, 2014). As crowdsourcing provides an opportunity to exploit collective knowledge that is commonly located outside of an organisation, it also allows organisations to foster innovation cheaply, flexibly and dynamically (Devece, Palacios \& Ribeiro-Navarrete, 2019). However, managing crowdsourcing is not as easy as it sounds.

There are four types of crowdsourcing, according to Prpić, Shukla, Kietzmann and McCarthy (2015):

- Crowd-voting: A crowd chooses from several alternatives;

- Idea crowdsourcing: A question is put to the crowd and the best answers are selected;

- Microtasking: The organisation divides a task into microtasks, each of which can easily be accomplished by individuals; and

- Solution crowdsourcing: A problem is stated and the crowd proposes solutions, mainly focused on ideas and solutions generated through crowdsourcing.

In this research, crowd-voting is chosen to complement the program recommendation system, due to the benefits of the crowd-voting in finding consensus among the knowledge experts collectively, on the prediction made by the system.

\subsection{Crowd-voting for Recommendation System}

In the past few years, research has been conducted specifically on the crowds of some well-known crowdsourcing applications to determine what motivates them to participate (Brabham, 2008) and (Hussain et al. 2018). While there are many common reasons for crowds to participate, there is no single motivator that seems to apply to all crowdsourcing applications. Motivations are diverse, individual and unique to the given crowdsourcing context (Devece, Palacios \& Ribeiro-Navarrete, 2019). On the other hand, crowd-vote contains a rich community of collaboration and evaluation, in which creators and adopters of creative content interact among themselves and with artefacts through overlapping relationships, such as affiliation, communication, affinity, and purchasing (Wang et al., 2015).

Crowd-vote, one of the four known types of crowdsourcing, is widely being used in businesses, such as strategy of business plan, strategy of product plan and project planning. In terms of strategy business plan, for example, crowd-vote gathers the information of product design and open an opportunity for the company to review it on strategy from outside ideas. The company is able to analyse their constraints, prepare portfolio and build the strategy of product line in strategy of product plan. Other than that, crowd-vote facilitates decision making in high level management and provides the evaluation of decision making in the stage of development (Hughart, 2013). The implementation of crowd-voting is most suitable because it leverages the community's judgement to organize, filter and stack the ranks' content. Crowd-vote generates the highest levels of participation, that becomes a rich knowledge source for a decision-making system. 
In this research, although student already got the prediction program recommendation from fuzzy logic inference system, student still can get other experts' opinion from the voting component as a part of getting professional advice before the student does his or her final decision. Kleinert, Volkmann, and Grünhagen (2018) reported that crowd-vote gives direct effect towards decision making from multiple outcomes of voting. A student is able to do assumption of his or her behaviour with positive relationship of voters' preferences. The implementation indicates an indirect influence of crowd-vote performance (Blohm et al., 2018).

The concept of crowd-voting is beneficial to decision making in many ways. This platform is chosen because it aligns to the research that was conducted by Qmarket (2018) who did a comparison among four types of crowdsourcing tools. The literature stated that the alternative of decision making can be done by crowd-vote since it has a goal to integrate diverse opinions, assessments, predictions and other information of contributors. It is good to evaluate and select alternatives. The system performance in crowd-voting can be found from literature review where it is proven as a powerful tool in decision making or information pooling in real world, especially in business and industry, such as community rating, score card rating, token voting, idea tournament and prediction market (Brabham, 2010).

\section{Methodology}

The research methodology is aimed to achieve the objectives mentioned in the Introduction. Figure 1shows the flow of research methodology. Prototype development is done by using ASP.Net and SQL database after considered many information from literature. Total number of 300 respondents tried the prototype that has extended of crowd-vote platform and involved with some feedback of 17 lecturers from UCSI, APU and UniKL. The implementation of crowdvote has been analyzed by using a survey and 76 out of 300 respondents (17 lecturers and 59 students).

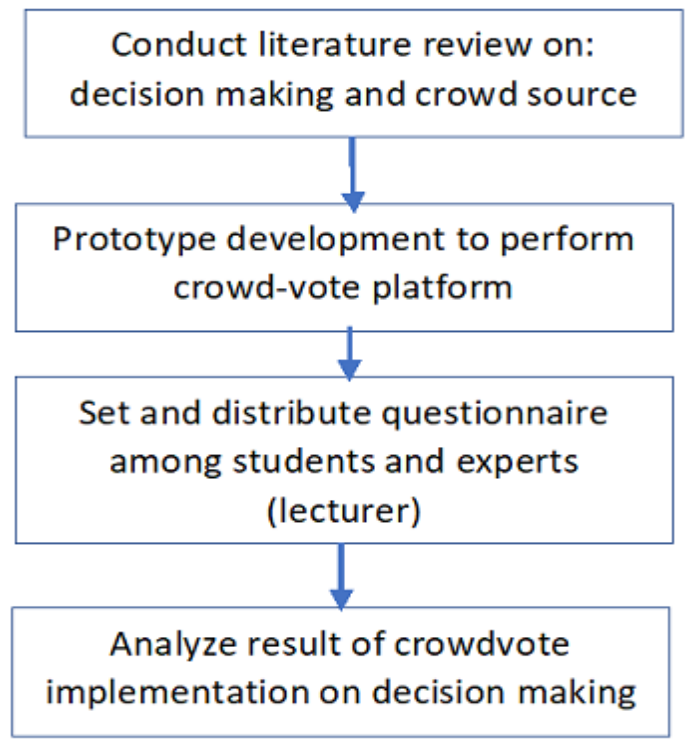

Figure 1.The flow of research methodology

In doing so, a qualitative data gathering was conducted through an empirical study on decision making of program selection among university students and the use of crowd-vote in businesses and education. This is followed by a system design of the user interface with crowd-vote component. There are three types or categories of users for this system, hence the interface differs based on their usage.

The prototype is then built on top of the system presented in the previous paper (Ismail, Basharirad \& Ismail, 2017; Ismail \& Ismail, 2018). The process of adding the functionality of displaying the outputs recommended by the fuzzy logic system, personality model, expert opinion and expert voting pool is done before the user acceptance testing on crowd-vote component is evaluated with Likert scale, psychometric scale that employs questionnaire survey.

\subsection{Research Settings and Participants}

A sample of 300 undergraduate students from different private universities in Kuala Lumpur and Selangor 
were involved in this research. A total of 43 respondents from UniKL, 48 respondents from Taylor's University, 30 respondents from UCSI University, 54 students from APU, 93 respondents from MMU and 32 respondents from SEGI university, make the proportion of this sample. Most of the respondents were studying Computer programs, such as Bachelor in Software Engineering, Bachelor of Mobile Computing, Bachelor of Business Information Technology, Bachelor of Multimedia, Bachelor of Networking in Cyber Security, Diploma in ICT and Diploma in Software Engineering.

Constructive questionnaire is selected for data gathering method with three sections designed: (a) Demographic information; (b) Particular result of primary school highest level of qualification; and (c) Type of students such as, indecisive, undecided and clear decision maker. In the first category, students were required to inform their background information, such as gender, email and type of school. The second category required the students to fill up their academic results from high/secondary school including the grades for each subject, the enrolled program, the highest level of qualification and CGPA. Lastly, the third category focused on identifying the type of students, whether they are 'clear' in making decision on program selection based on internal factors, and by calculating the highest number of respondents chosen for a total of seven questions. The external factors include 'university' (identified in question C3), 'advising system' (question C4), 'family' (question C5), 'friend or peer' (question C6) and 'agent' (question C7), as shown in Table 1.

Table 1.Example of Questions in Section C

QUESTION
CODE

C1 I am clear that I choose a correct program for my future.

C2 I choose the program by my own decision.

C3 I am clear about my course and program structure.

C4 I choose the program based on advisor's recommendation.

C5 I choose the program based on family's recommendation.

C6 I choose the program based on friend's or peer's recommendation.

C7 I choose the program based on agent's recommendation.

C8 I am certain that my qualification matches the program.

C9 During program selection, I was certain about my result in high/secondary school; it matches the current program I chose

C10 During program selection at the beginning, I was ready to continue with my study in university.

C11 I found this program suitable to my personality and skills.

C12 I am happy and enjoy my study.

\subsection{System Interface Design}

Figure 2 shows the crowd-vote component on student's page, which displays the overall result of student's type based on student's qualification, personality, his or her "skills and interests" and system recommendation for suitable program based on fuzzy logic method. It shows the summary of how student can reach the recommendation via the web-based system. Student can check the suggestion on the program selection from 'crowd-vote' function. 


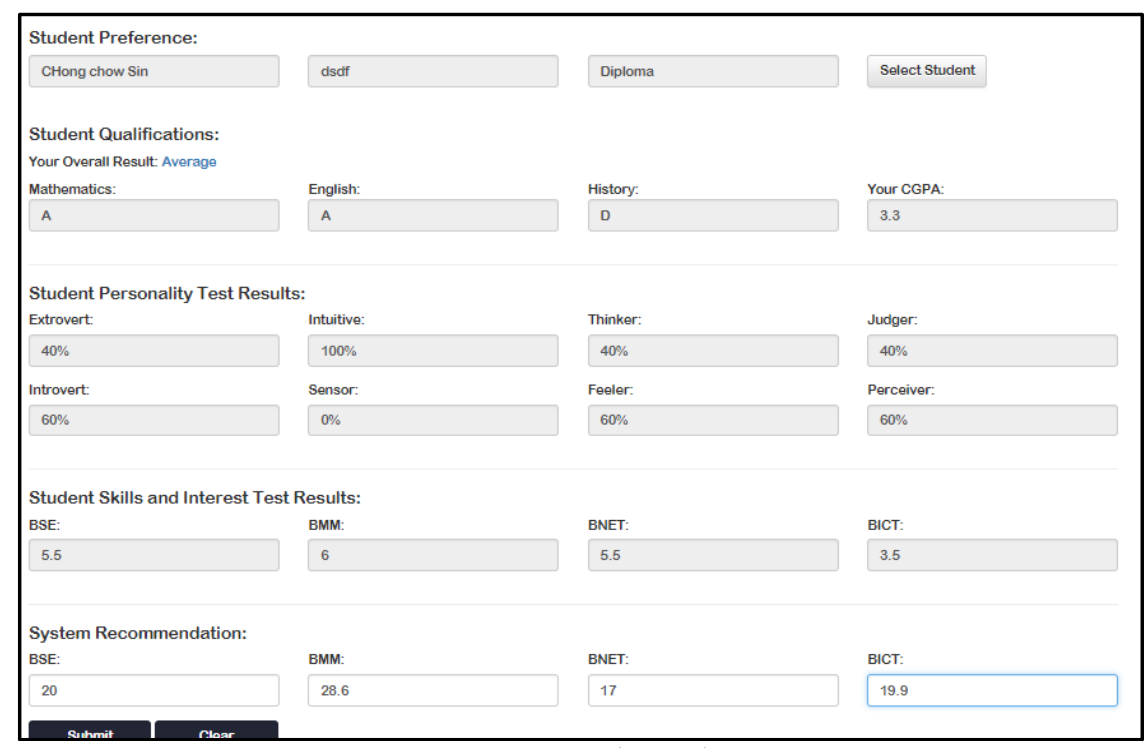

Figure 2.Crowd-vote in student's page

As shown in the example in Figure 3, this student has an average qualification. The CGPA is 3.30 and is considered as having good performance in his or her current enrolled program. Student's score in the component of 'skills and interests' is more to programs like network and software engineering, and the personality preference is INFP. Basically, people of INFP personality is an insightful enhancer. Based on personality and university program model, this kind of person is suitable for program in ICT and Multimedia. The predicted result recommended twenty-eight point six percent (28.6\%) in Multimedia, twenty percent (20\%) in Software Engineering and seventeen percent (17\%) in ICT.

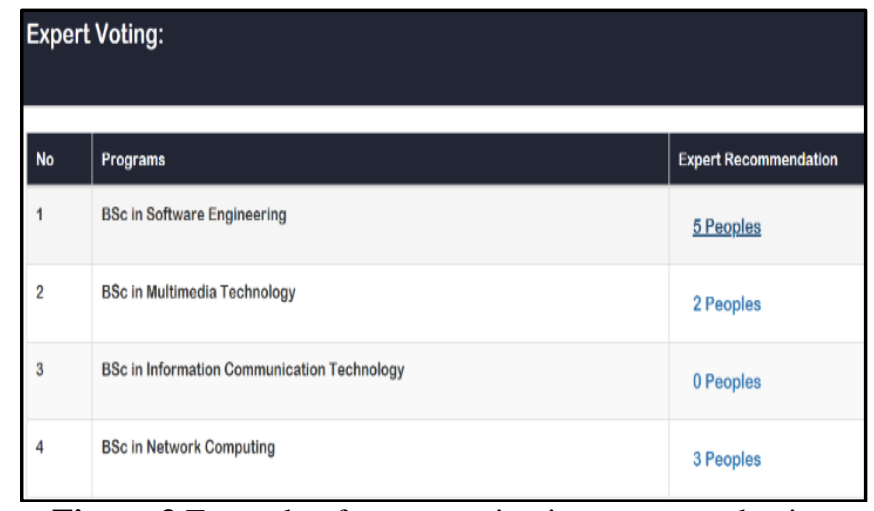

Figure 3.Example of expert voting in program selection

Students can view the number of expert voters for the program recommendation in their account, as shown in Figure 3. This five experts are APU's lecturers from Faculty of Information System and Software Engineering and UCSI's lecturers from Faculty of Business and Information System. In this figure, there are five people who voted on software engineering, three people voted on network computing and only two people voted on multimedia technology to one of software engineering student who is taking Software Engineering program. Here, students can click on the vote in each selected program to view the comment or advice from the voters.

Figure 4 shows an example of expert voters from a sample of lecturers in APU and UCSI University. The expert can be any people who are involved in university advising system, such as lecturers, head of school, alumni members and others. They have different ideas and perspectives based on their point of view towards program recommendation. They used the prediction result from three domain components to do deductive reasoning and provide the opinions and answer students' requests. For example, a student may ask on what program that offers better career in terms of high pay of salary and the difficulty level of learning in each program. System automatically sort the number of program that has the highest voting and students can make their deductive reasoning to make their decision based on the experts' comments. 


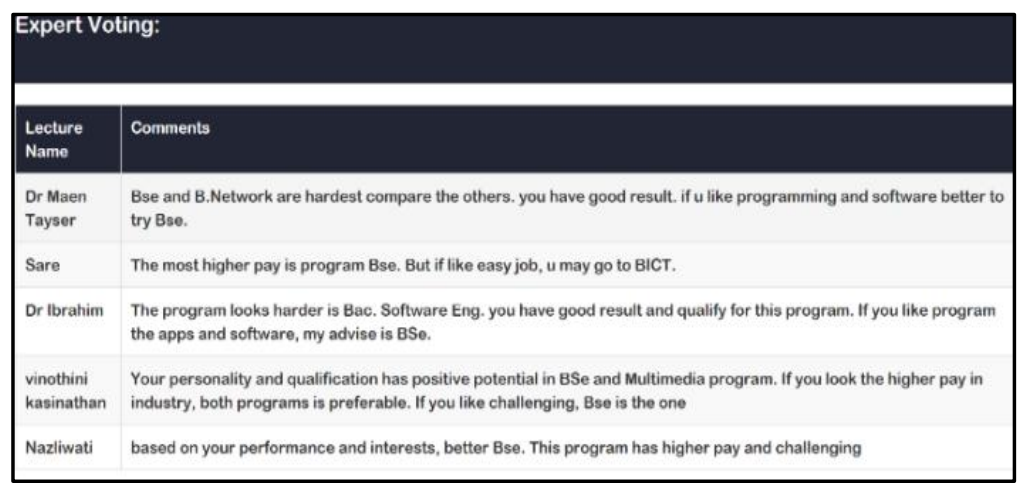

Figure 4.Example of experts' comments from their voting

\subsection{Crowd-vote Evaluation}

Descriptive survey and system testing on the prototype were conducted among expert users (i.e. lecturers) and 300 students. Descriptive survey is commonly organised as statistics to obtain certain interesting findings. Figure 5 shows an example of questions from this survey using 5-Likert scale data gathering on crowd-vote implementation as a decision making supporter.

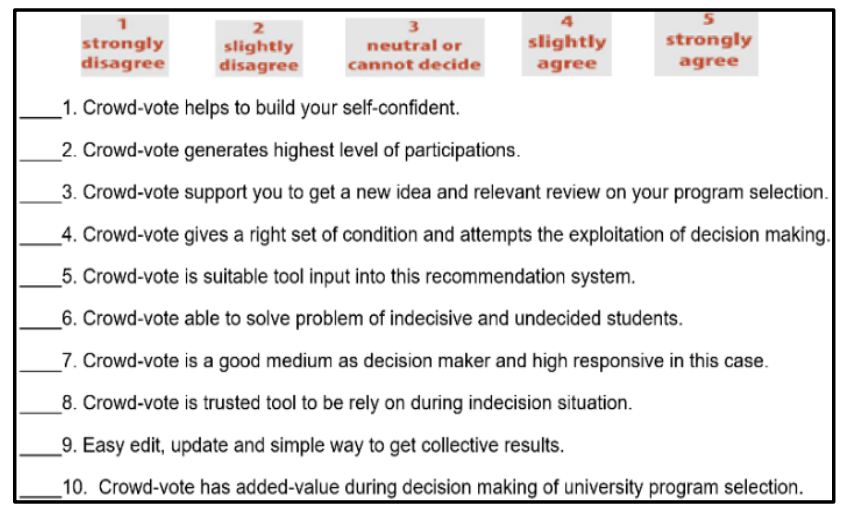

Figure 5.Example questions in evaluation survey

On the other hand, Table 2 shows an excerpt of user acceptance testing result on crowd-vote components constructed from experts, which purposely to make sure the overall aspects turned into fine work. Unit testing has also been used to test an individual unit of the software to make sure it performs appropriately.

Table 2.User Acceptance Testing on Crowd-vote Component

Test case description: Log in, search user, profile CRUD, voting pool

\begin{tabular}{|c|c|c|c|c|c|}
\hline S No. & ACTION & INPUT & $\begin{array}{l}\text { EXPECTED } \\
\text { OUTPUT }\end{array}$ & $\begin{array}{l}\text { ACTUAL } \\
\text { OUTPUT }\end{array}$ & $\begin{array}{l}\text { TEST } \\
\text { COMMENTS }\end{array}$ \\
\hline 1 & $\begin{array}{l}\text { Launch } \\
\text { application }\end{array}$ & $\begin{array}{l}\text { http://localhost: } \\
\text { 38249/index.aspx }\end{array}$ & $\begin{array}{l}\text { The homepage of } \\
\text { expert advising } \\
\text { system }\end{array}$ & $\begin{array}{l}\text { The homepage } \\
\text { of expert } \\
\text { advising system }\end{array}$ & $\begin{array}{l}\text { [KakWati } \\
\text { 8/7/2017 } \\
\text { 3.40pm: Launch } \\
\text { successful] }\end{array}$ \\
\hline 2 & $\begin{array}{lr}\text { Enter } & \text { correct } \\
\text { user ID } & \text { and } \\
\text { password. } & \text { Hint } \\
\text { of user ID. } & \end{array}$ & $\begin{array}{l}\text { Email: } \\
\text { nazliwati@ucsi } \\
\text { university.edu.my } \\
\text { Password: } * * *\end{array}$ & $\begin{array}{l}\text { Log in success } \\
\text { including testing } \\
\text { error handler }\end{array}$ & $\begin{array}{l}\text { Error handler } \\
\text { forget password } \\
\text { and retrieve from } \\
\text { email }\end{array}$ & $\begin{array}{l}\text { [Kak Wati } \\
\text { 8/7/2017 } \\
\begin{array}{l}\text { 3.42pm: Login } \\
\text { successful] }\end{array}\end{array}$ \\
\hline 3 & $\begin{array}{l}\text { Search student } \\
\text { ID }\end{array}$ & $\begin{array}{l}\text { http://localhost: } \\
\text { 38249/LectureMenu.a } \\
\text { spx }\end{array}$ & $\begin{array}{l}\text { The table contains } \\
\text { student ID, name, } \\
\text { qualification, } \\
\text { result of } \\
\text { personality test, } \\
\text { system } \\
\text { recommendation }\end{array}$ & $\begin{array}{l}\text { The table } \\
\text { contains student } \\
\text { ID, name, } \\
\text { qualification, } \\
\text { result of } \\
\text { personality test, } \\
\text { system } \\
\text { recommendation }\end{array}$ & $\begin{array}{l}\text { [Kak Wati } \\
\text { 8/7/2017 } \\
\text { 3.55pm: Valid } \\
\text { studentId4, } \\
\text { studentId360, } \\
\text { studentId14, } \\
\text { studentId344] }\end{array}$ \\
\hline 4 & Voting pool & http://localhost:38249 & Personality & Personality result & {$[\mathrm{Kak}$} \\
\hline
\end{tabular}




\begin{tabular}{|c|c|c|c|}
\hline /LectureMenu/vote.as & system & system & $8 / 7 / 2017$ \\
\hline $\mathrm{px}$ & $\begin{array}{l}\text { recommendation. } \\
\text { Student's enquiry. }\end{array}$ & $\begin{array}{l}\text { recommendation. } \\
\text { Student's } \\
\text { enquiry. }\end{array}$ & $\begin{array}{l}\text { 3.56pm: Valid } \\
\text { studentId4, } \\
\text { studentId360, } \\
\text { studentId14, } \\
\text { studentId344] }\end{array}$ \\
\hline $\begin{array}{l}\text { http://localhost:38249 } \\
\text { /LectureMenu/vote1.a } \\
\text { spx }\end{array}$ & $\begin{array}{l}\text { View other } \\
\text { experts' votes and } \\
\text { comments }\end{array}$ & $\begin{array}{l}\text { View other } \\
\text { experts' votes } \\
\text { and comments }\end{array}$ & $\begin{array}{l}\text { [Kak Wati } \\
\text { 8/7/2017 } \\
\text { 4.01pm: } \\
\text { successful] }\end{array}$ \\
\hline
\end{tabular}

Experts required the university program structure to be included in their page as references and to have the system to possibly provide chat relay as communicator between the experts and students. The chat relay is an interactive platform to replace the function of capturing and responding to student enquiries. A total number of expert users is 6 lecturers from UCSI university, 6 lecturers from APU and 5 lecturers from UniKL.

The system testing has been done in some test cases, such as log in, search the student's profile and information, view system recommendation, vote process and voted result. The experts are compulsory to drop their comments before they need to vote the respective program and are required to reply student's enquiry (if available). The experts can view the details of system recommendation, the students' results on personality model, 'skills and interests' and prospect career, including the students' qualification.

\section{Results and Findings}

There are two sets of questionnaires distributed specific for crowd-vote component, in which the first set is to investigate three categories of decision makers: (1) clear decision-made students, (2) indecisive students, and (3) undecided students. The result from Section $\mathrm{C}$ of this questionnaire (as shown in Table 1) shows that a total of 18.2 percent $(18.2 \%)$ of students were clear or made their own decision, 52 percent (52\%) are indecisive students, and 30.1 percent $(30.1 \%$ ) are undecided students, among a total of 300 respondents. It also shows most of clear-minded students made the decision influenced by external variables, such as university (22.4\%) and family (17\%). The result shows the external factors, such as friends or peers is 65 percent (65\%), and agents is 63 percent $(63 \%)$, are the influence factors for choice made in the group of indecisive and undecided students cognitively.

Another set of questionnaire is distributed to evaluate the effectiveness of crowd-vote in advising system among 29 male students and 30 female university students. The result showed positive response from various aspects as issued in survey evaluation questions. A total of 79 percent (79\%) of these students strongly agreed that crowd-vote build their self-confidence during decision making on suitable program for them to choose, 48 percent $(48 \%)$ strongly agreed that crowd-vote solves their indecisiveness in decision-making, while 64 percent (64\%) strongly agreed that crowd-vote is a good medium and trusted tool as decision maker. In addition to that, 27 percent $(27 \%)$ strongly agreed, and 32 percent (32\%) agreed that crow-vote is an easy tool to get solid data collection on their decision process. A total of 25 percent (25\%) strongly agreed, and 12 percent (12\%) agreed that crowd-vote has added value in university program recommendation system, which supports them to get the idea and relevant review from participants.

Overall, the experts agreed that the idea of including this crowd-vote component to support the recommendation system is good, because it builds the self-confidence among the students, and offers direct communication in the advising system.

\section{Discussion}

Based on the results from investigation of research, there is an existence in the indecision among university students during program selection. The use of crowd-vote tool is recommended as a part of advising students on program options, and research suggested that this tool is a relevant component to support decision making among students especially to the freshmen. Crowdsourcing is a powerful decision making tool as it harvest the knowledge of experts, which contains services, ideas or content by soliciting contributions from a large group of people. The most popular implementation can be found in businesses, but this research implements crowd-vote as part of an expert advising system. Crowd-vote has the capability to get the possible comments or ideas from potential experts and targeted people during decision making in the earlier stage, adding the knowledge value to the users. 
The implementation of crowd-vote is one of alternative ways to provide self-confidence among students and it is a one-stop platform between the university experts and potential students. Different types of communication will resonate better with students, depending on where they are in their search and the application process. For example, if the university knows the time of year of students, typically it makes their final enrolment decisions and it can help to establish a timeline around yield activity and outreach strategy. The current research includes crowd-voting because time and communication are crucial during the decision making.

\section{Conclusion}

This research successful proved that crowd-vote is a popular practice in the process of 'deciding on' or 'making' university program selection because it generates the highest level of participation. Therefore, it is possible to equip any expert advising system with crowd-vote to build one platform of direct communication that will create the fastest response among the advisors or potential experts from the particular universities. It is also possible to increase the motivation and self-confidence level on decision making amongst undecided or indecisive students. This shows the importance of knowledge sharing among experts during crowd-voting in boosting self-confidence among students.

\section{Acknowledgment}

The authors would like to express appreciation for the support of the sponsor [UniKL Short Term Research Grant $=$ str19040].

\section{References}

1. Blohm, I., S. Zogaj, U. Bretschneider and J.M. Leimeister. 2018. How to Manage Crowdsourcing Platforms Effectively? California Management Review, 60(2): 122-149.

2. Brabham, D.C. 2008. Moving the crowd at iStockphoto: The composition of the crowd at motivations for participation in a crowdsourcing application. First Monday, 13(6).

3. Brabham, D.C. 2010. Moving the crowd at Threadless. Information Communication Society, 13(8): 1122-1145.

4. Callaghan, C.W. 2014. Solving Ebola, HIV, antibiotic resistance and other challenges: The new paradigm of probabilistic innovation. American Journal of Health Sciences, 5(2): 165-178.

5. Callaghan, C.W. 2016. A new paradigm of knowledge management: Crowdsourcing as emergent research and development. Southern African Business Review, 20.

6. Daramola, O., O. Emebo and I. Afolabi, C. Ayo. 2014. Implementation of an intelligent course advisory expert system. International Journal of Advanced Research in Artificial Intelligence 3(5): 6-12.

7. Devece, C., D. Palacios and B. Ribeiro-Navarrete. 2019. The effectiveness of crowdsourcing in knowledge-based industries: the moderating role of transformational leadership and organisational learning. Economic Research-Ekonomska Istraživanja, 32(1): 335-351.

8. Dimitrova, S. and E. Scarso. 2017. The impact of crowdsourcing on the evolution of knowledge management: Insights from a case study. Knowledge and Process Management, 24(3).

9. Feghali, T., I. Zbib and S. Hallah. 2011. A web-based decision support tool for academic advising. Educational Technology \& Society, 14(1): 82-94.

10. Gordon, V.N. and G.E. Steele. 2015. The undecided college student: An academic and career advising challenge. Charles C Thomas Publisher.

11. Hanson, R. 2000. Shall we vote on values, but bet on beliefs? http:// hanson.gmu.edu/futarchy2000.pdf.

12. Hughart, D.H. 2013. Crowdsourcing Applications of Voting Theory. Doctoral Dissertation, University of Oregon, Eugene, USA.

13. Hussain, A., Mkpojiogu, E.O.C., Jamaisse, A., Mohammed, R. (2018). Grab mobile app: A UX assessment on mobile devices. Journal of Advanced Research in Dynamical and Control Systems, 10 (10), pp. 1233-1238.

14. Iatrellis, O., A. Kameas and P. Fitsilis. 2017. Academic Advising Systems: A Systematic Literature Review of Empirical Evidence. Education Sciences, 7(90).

15. Islam, R., Ghani, A.B.A., Kusuma, B., Theseira, B.B. (2016). Education and human capital effect on Malaysian economic growth. International Journal of Economics and Financial Issues, 6 (4), pp. 17221728.

16. Ismail, S., B. Basharirad and S. Ismail. 2017. Significant of MBTI personality model on decision making in university program selection. International conferences on Information Technology, Information Systems and Electrical Engineering (ICITISEE), Yogyakarta, Indonesia.

17. Ismail, S. and S. Ismail. 2018. Methodology to Develop Neuro-Fuzzy Logic Expert Advising System in 
University. IEEE Student Conference on Research and Development (SCOReD), Selangor, Malaysia: 1-6.

18. Johnson, N.L. 1998. Collective problem solving. Los Alamos National Laboratory Working Paper LAUR-98-2227.

19. Kleinert, S., C. Volkmann and M.Grünhagen 2018. Third-party signals in equity crowdfunding: the role of prior financing. Small Business Economics: 1-25.

20. Kochugovindan, S. and N.J. Vriend. 1998. Is the study of complex adaptive systems going to solve the mystery of Adam Smith's “invisible hand"? The Independent Review, 3(1): 53-66.

21. Mitchell, M. 1996. An Introduction to Genetic Algorithms, London: MIT Press.

22. Prpić, J., P. Shukla, J.H. Kietzmann and I.P. McCarthy. 2015. How to work a crowd: Developing crowd capital through crowdsourcing. Business Horizons, 58(1): 77-85.

23. Qmarket.net. 2018. Crowdsourcing. https://www.qmarkets.net/use-cases/bymethodology/crowdsourcing/.

24. Smith, A. 2003. The Wealth of Nations, Bantam Dell, New York.

25. Surowiecki, J. 2004. The Wisdom of Crowds. Little, Brown, London.

26. Unelsrød, H.F. 2011. Design and Evaluation of a Recommender System for Course Selection. Master's Thesis, Institutt for Datateknikk og Informasjonsvitenskap, Trondheim, Norway.

27. Wang, L., T. Lou, Y. Huang and N. Contractor. 2015. Intelligence of Crowd: Could Voting Predicts Product Sales? Collective Intelligence. 